\title{
RESEARCH
}

Open Access

\section{The three-dimensional morphology of mandible and glenoid fossa as contributing factors to menton deviation in facial asymmetry-retrospective study}

Min-Hee Oh and Jin-Hyoung Cho* (1)

\begin{abstract}
Background: The aim of this study is to evaluate whether the three-dimensional (3D) morphology of the mandibular condyle, glenoid fossa, and mandible correlated with menton deviation in facial asymmetry.

Subjects and methods: Thirty adults (15 males and 15 females; mean age, $23.2 \pm 3.8$ years) with facial asymmetry were included. Linear, angular, and volumetric measurements of the 3D morphology of the mandibular condyle, glenoid fossa, and mandible were recorded using computed tomography (CT) images. The right/left differences were obtained by subtracting the left value from the right value, and an independent $t$ test was used to compare the differences between the females and males. Multiple regression analysis was performed to identify the correlation between the right/left difference of the 3D morphology and menton deviation.

Results: The results of the comparative analysis did not show any statistical difference between the females and males $(P>.05)$, so the females and males were combined. Multiple regression analysis for the mandibular condyle, glenoid fossa, and mandible showed that neck length, ramus length, and frontal ramal inclination had positive influences on menton deviation, with $76.5 \%$ of explanatory power. The neck length and head volume of the mandibular condyle when only the mandibular condyle was considered, and the ramus length and frontal ramal inclination when only the mandible was considered had positive influence on menton deviation with $69.9 \%$ and $68.6 \%$ explanatory power, respectively. On the other hand, when only considering glenoid fossa, the glenoid fossa had little effect on menton deviation with $15.7 \%$ of explanatory power.
\end{abstract}

Conclusions: In facial asymmetry, the right/left differences in mandibular condyle and mandible have more impact on the menton deviation than the right/left differences in glenoid fossa.

Trial registration: CNUDH, CNUDH-EXP-2017-016. Registered 28 September 2017

Keywords: Facial asymmetry, Menton deviation, 3D morphology, Computed tomography

\footnotetext{
* Correspondence: jhcho@jnu.ac.kr

Department of Orthodontics, School of Dentistry, Dental 4D Research

Institute, Dental Science Research Institute, Chonnam National University, 77 Yongbong-ro, Buk-gu, Gwangju 61186, Korea
}

\section{Springer Open}

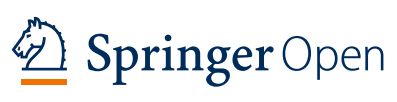

(c) The Author(s). 2020 Open Access This article is licensed under a Creative Commons Attribution 4.0 International License, which permits use, sharing, adaptation, distribution and reproduction in any medium or format, as long as you give appropriate credit to the original author(s) and the source, provide a link to the Creative Commons licence, and indicate if changes were made. The images or other third party material in this article are included in the article's Creative Commons licence, unless indicated otherwise in a credit line to the material. If material is not included in the article's Creative Commons licence and your intended use is not permitted by statutory regulation or exceeds the permitted use, you will need to obtain permission directly from the copyright holder. To view a copy of this licence, visit http://creativecommons.org/licenses/by/4.0/. 


\section{Background}

Facial asymmetry is influenced more by the lower third of the face than by the upper and middle thirds of the face $[1,2]$. The mandibular condyle has been known to affect the asymmetry of the mandible as an important growth site in the mandible [3, 4]. In addition, mandibular asymmetry has been shown to be influenced by other various factors, such as condylar hyperplasia [5], childhood condylar fractures [6], condylar resorption [7], and internal derangement of the temporomandibular joint (TMJ) [8]. However, most studies [5-8] used two-dimensional radiographs that have several limitations including distortion, magnification, and lack of clarity.

To overcome these limitations, three-dimensional (3D) computed tomography (CT) has been used. Previous studies $[9,10]$ have shown that the cranial base and the mandible can vary between the deviated and the non-deviated sides. You et al. [11] investigated the mandibular morphology in patients with facial asymmetry and mandibular prognathism using CT data and reported that the length of the mandibular condyle and mandibular body were significantly longer on the non-deviated side than on the deviated side. Oh et al. [12] compared the 3D structure of the mandibular condyles between adults with and without facial asymmetry and reported that menton deviation was associated with right/left differences caused by a smaller condyle, particularly in condylar neck length and neck and head volume, on the deviated side. Moreover, Ikeda et al. [13] found that 3D mandibular morphologic asymmetry was associated with condylar movement in patients with mandibular asymmetry.

In addition, several previous studies have suggested that the shape [14] and volume $[14,15]$ of the glenoid fossa are necessary to make the diagnosis and administer proper treatment in patients with facial asymmetry. Cho et al. [14] evaluated the effect of the glenoid fossa on menton deviation in facial asymmetry. The vertical position and the depth of the glenoid fossa showed significant differences between the symmetry and asymmetry groups. Kim et al. [15] suggested that the volume of the glenoid fossa, as well as that of the mandibular condyle, should be considered in facial asymmetry.

A literature review of recent CT [11-15] studies on the correlation between 3D morphology of the TMJ and facial asymmetry revealed several measurements that differed significantly in facial asymmetry. However, few studies have simultaneously evaluated the contribution of the mandible and glenoid fossa to menton deviation. The purpose of this study was to identify the factors contributing to menton deviation by evaluating the correlation between menton deviation and 3D morphologies of the mandibular condyle, glenoid fossa, and mandible in facial asymmetry.

\section{Methods}

Ethical approval for this retrospective cohort study was obtained (CNUDH-EXP-2017-016). The sample size of thirty adults was determined using the G*Power 3.1.9.2 software (University of Kiel, Kiel, Germany), with an effect size $=4.92$ derived from the preliminary data, $\alpha=$ 0.05 , and $1-\beta=0.95$. Based on a previous study $[12,14]$, thirty adults (15 males and 15 females) with skeletal class I or III malocclusion were included. The first selection was performed for subjects with menton deviation on postero-anterior (PA) radiographs exceeding $2^{\circ}$ toward the left [16]. Menton deviation was defined as the angle between the vertical reference line drawn from the crista galli to the anterior nasal spine (ANS) and the line drawn from the ANS to the menton on PA radiographs $[17,18]$. Finally, the amount of menton deviation was confirmed using CT images. In CT images, menton deviation was defined as the angle between the midsagittal reference plane (MSR plane) and the line drawn from the ANS to the menton on frontal view. The MSR plane was defined as the plane perpendicular to Frankfort horizontal plane (FH plane) passing through the crista galli and opisthion [14]. The right side was the non-deviated side, and the left side was the deviated side because the subjects in this study had menton deviations only toward the left.

The inclusion criteria were subjects over 20 years old with available frontal and lateral cephalograms and CT images acquired before treatment. The exclusion criteria were orthodontic treatment, orthognathic surgery, prosthetic treatment for more than a single crown, TM) morphological changes, signs or symptoms of temporomandibular disorders, systematic arthritis, facial trauma, craniofacial anomaly, functional discrepancies, functional crossbite, and skeletal class II malocclusion.

The CT images were acquired using a CT scanner (Light Speed QX/i, GE Medical Systems, Milwaukee, WI, USA) before treatment. A more detailed explanation of CT image acquisition can be found in previous studies $[12,14]$. The V-works 4.0 software (CyberMed Inc., Seoul, Korea) was used to reconstruct the 3D images from the digital imaging and communication in medicine data. Definitions of the landmarks are described in Table $1[12,14]$. The 3D reference planes were constructed. The FH plane passed through the right orbitale and right and left porions. The MSR plane was the plane perpendicular to the $\mathrm{FH}$ plane passing through the crista galli and opisthion. The anteroposterior reference plane (PO plane) was the plane perpendicular to the $\mathrm{FH}$ plane passing through the right and left porions.

In order to precisely identify the landmarks, the mandible was separated from the whole volume rendering image by removing the overlapping areas as reported in a previous study [12] and exporting it into a selection of 
Table 1 The landmarks used in this study

\begin{tabular}{lll}
\hline Landmarks & Abbreviation & Description \\
\hline Crista galli & $\mathrm{Cg}$ & The most superior point of the crista galli of the ethmoid bone \\
Opisthion & $\mathrm{Op}$ & The most posterior point on the posterior margin of the foramen magnum \\
Porion & $\mathrm{Po}$ & The highest point on the roof of the external auditory meatus \\
Orbitale & $\mathrm{Or}$ & The deepest point on the infraorbital margin \\
Condylion superius & $\mathrm{Cd}_{\text {sup }}$ & The most superior point of the condyle head \\
Condylion medialis & $\mathrm{Cd}_{\text {med }}$ & The most medial point of the condyle head \\
Condylion lateralis & $\mathrm{Cd}_{\text {lat }}$ & The most lateral point of the condyle head \\
Condylion anterius & $\mathrm{Cd}_{\text {ant }}$ & The most anterior point of the condyle head \\
Condylion posterius & $\mathrm{Cd}_{\text {post }}$ & The most posterior point of the condyle head \\
Sigmoid notch & $\mathrm{S}$ & The most inferior point of sigmoid notch \\
Gonion lateralis & $\mathrm{Golat}$ & The most lateral point of the gonion area \\
Gonion posterius & $\mathrm{Go}$ post & The most posterior point of the gonion area \\
Gonion inferius & $\mathrm{Go}$ inf & The most inferior point of the gonion area \\
Antegonion & $\mathrm{Ag}$ & The deepest point of antegonial notch of mandible \\
Menton & $\mathrm{Me}$ & The most inferior point on mandibular symphysis \\
Roof of glenoid fossa & $\mathrm{RG}$ & The highest point on the roof of the glenoid fossa \\
Articular eminence & $\mathrm{AE}$ & The most inferior point on the articular tubercle
\end{tabular}

demand (SOD) file. Moreover, the neck SOD file containing the condylar process above the sigmoid notch was separated by a plane passing through the most inferior point of sigmoid notch while parallel to the $\mathrm{FH}$ plane. The head SOD file, which included the upper part of the condylar process, was separated by a plane passing through the most contracted part of the condylar neck while parallel to the FH plane (Fig. 1) [12]. The neck and head SOD files were converted into a 3D surface shaded display (SSD) model to measure the volume of the 3D object model.

The definition of measurements was described in Table 2 and Figs. 2 and 3 [12, 14]. All measurements, including linear measurements, were measured on a
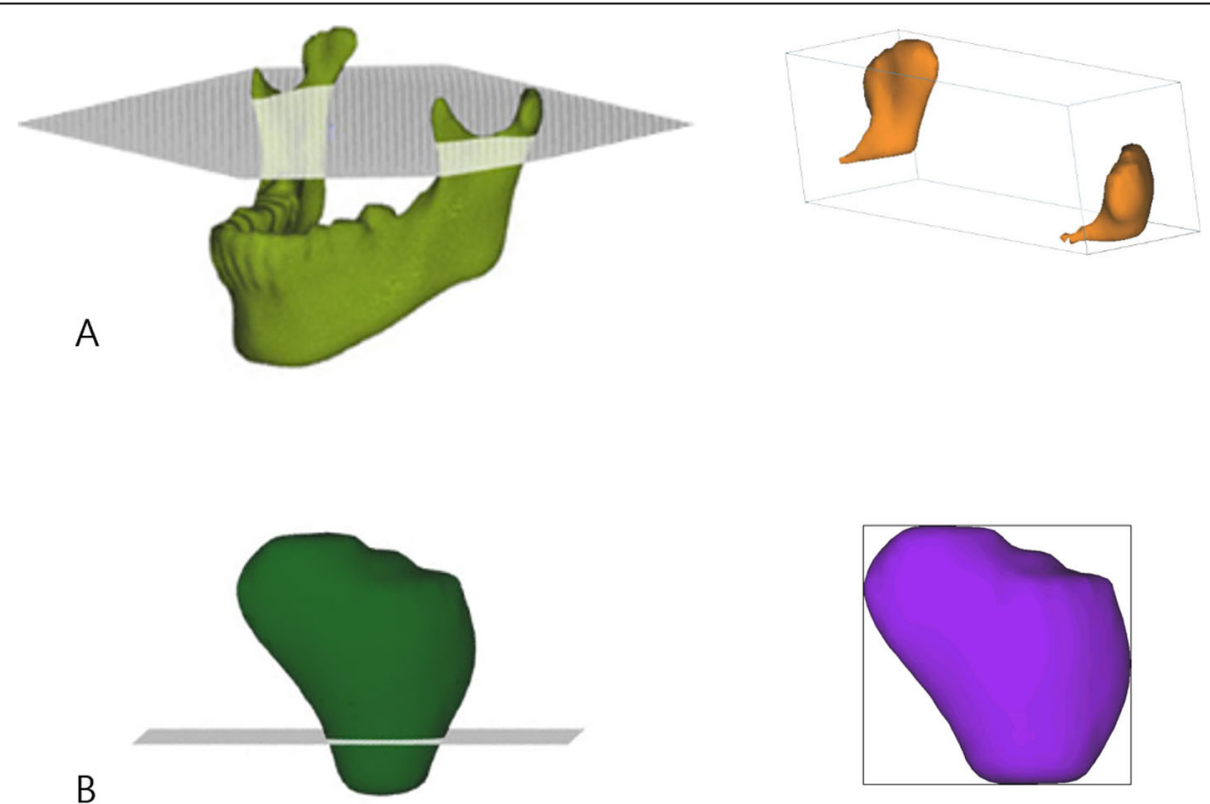

Fig. 1 Formation of three-dimensional images. The neck (a) and head (b) selection of demand (SOD) files were separated from the mandible SOD file that was separated from the whole volume rendering image by removing the overlapping areas using the sculpt functions of the $V$ works program (CyberMed Inc., Seoul, Korea) (reproduced with permission [12]) 
Table 2 Definition of the measurements used in this study

\begin{tabular}{|c|c|}
\hline Measurements & Definition \\
\hline \multicolumn{2}{|l|}{ Mandibular condyle } \\
\hline Mediolateral dimension (mm) & $\mathrm{Cd}_{\text {med }}$ to $\mathrm{Cd}_{\text {lat }}$ \\
\hline Anteroposterior dimension (mm) & $\mathrm{Cd}_{\text {ant }}$ to $\mathrm{Cd}_{\text {post }}$ \\
\hline Neck length (mm) & $\mathrm{Cd}_{\text {sup }}$ to $\mathrm{S}$ \\
\hline Mediolateral condylar position (mm) & $\mathrm{Cd}_{\text {med }}$ to MSR plane \\
\hline Condylar angle to $\mathrm{FH}\left({ }^{\circ}\right)$ & $\left(\mathrm{Cd}_{\text {med }}-\mathrm{Cd}_{\mathrm{lat}}\right)$ to $\mathrm{FH}$ plane \\
\hline Condylar angle to $\mathrm{PO}\left(^{\circ}\right)$ & $\left(\mathrm{Cd}_{\text {med }}-\mathrm{Cd}_{\text {lat }}\right)$ to PO plane \\
\hline Condylar angle to MSR $\left(^{\circ}\right)$ & $\left(\mathrm{Cd}_{\text {med }}-\mathrm{Cd}_{\mathrm{lat}}\right)$ to MSR plane \\
\hline Neck volume $\left(\mathrm{mm}^{3}\right)$ & $\begin{array}{l}\text { The volume of condylar neck } \\
\text { above } S\end{array}$ \\
\hline Head volume $\left(\mathrm{mm}^{3}\right)$ & $\begin{array}{l}\text { The volume of condylar head } \\
\text { above most constriction point } \\
\text { of condylar neck }\end{array}$ \\
\hline \multicolumn{2}{|l|}{ Glenoid fossa } \\
\hline Vertical position of RG to $\mathrm{FH}(\mathrm{mm})$ & RG to $\mathrm{FH}$ plane \\
\hline Vertical position of $\mathrm{AE}$ to $\mathrm{FH}$ (mm) & $\mathrm{AE}$ to $\mathrm{FH}$ plane \\
\hline Depth of glenoid fossa (mm) & AE to RG parallel to MSR plane \\
\hline Sagittal position of RG to PO (mm) & RG to $\mathrm{PO}$ plane \\
\hline Sagittal position of AE to PO (mm) & AE to $\mathrm{PO}$ plane \\
\hline Anterior angle of $\mathrm{GF}$ to $\mathrm{FH}\left({ }^{\circ}\right)$ & (RG-AE) to FH plane \\
\hline \multicolumn{2}{|l|}{ Mandible } \\
\hline Ramus length (mm) & $\mathrm{Cd}_{\text {sup }}-\mathrm{Go}_{\text {inf }}$ \\
\hline Frontal ramal inclination $\left(^{\circ}\right)$ & $\left(\mathrm{Cd}_{\text {lat }}-\mathrm{Go}_{\text {lat }}\right)$ to MSR plane \\
\hline Lateral ramal inclination $\left(^{\circ}\right)$ & $\left(\mathrm{Cd}_{\text {post }}-\mathrm{Go}_{\text {post }}\right)$ to $\mathrm{FH}$ plane \\
\hline Body length (mm) & $\mathrm{Go}_{\text {post }}-\mathrm{Me}$ \\
\hline Body height (mm) & $\begin{array}{l}\text { Canine cusp tip to Mandibular } \\
\text { plane }\end{array}$ \\
\hline
\end{tabular}

FH Frankfort horizontal plane, $P O$ anteroposterior reference plane, $M S R$ midsagittal reference plane, $R G$ roof of glenoid fossa, $A E$ articular eminence, $G F$ glenoid fossa, $C d_{\text {med }}$ condylion mediais, $C d_{\text {lat }}$ condylion lateralis, $C d_{\text {ant }}$ condylion anterius, $C d_{\text {post }}$ condylion posterius, $C d_{\text {sup }}$ condylion superius, $S$ sigmoid notch, $G o_{\text {inf }}$ gonion inferius, $G o_{\text {lat }}$ gonion lateralis, $G o_{\text {post }}$ gonion posterius, Me menton

three-dimensional coordinate system, indicating 3D linear, angular, and volumetric measurements. The volumes of the neck and head were calculated automatically using the volume measure function of the $\mathrm{V}$-works program with the SSD model, which is the 3D object model of neck and head.

\section{Statistical analysis}

Statistical analyses were performed using IBM SPSS Statistics (version 23.0; IBM Co., Armonk, NY, USA). All measurements were performed by a single operator (JHC). Twenty images were randomly selected and the measurements were performed twice with a 2-week interval between the measurements. The intraclass correlation coefficient (ICC) was performed to assess reliability. The ICC $(>0.983)$ indicated excellent intra-observer reliability.
The right/left differences were obtained by subtracting the left value from the right value. Thus, if the value on the deviated side was smaller than that on the nondeviated side, the right/left differences were described as positive $(+)$, otherwise, they were described as negative $(-)$. The results of comparative analysis did not show any statistical difference between the females and males $(P>.05)$, so the females and males were combined.

Multiple regression model was used to determine the effect of right/left differences of the measured variables on the menton deviation. A multiple regression model using backward elimination was used to identify the causes of menton deviation. Multiple regression analyses were performed four times for the different conditions: (1) for the mandibular condyle, glenoid fossa, and mandible $(n=30)$; (2) for the mandibular condyle only $(n=30)$; (3) for the glenoid fossa only $(n=30)$; and (4) for the mandible only $(n=30)$.

\section{Results}

The demographic characteristics of the subjects, including gender, age, amount of menton deviation, ANB, and SN-MP are presented in Table 3. The right/left differences of all measurements are shown in Table 4.

The regression equation between menton deviation and the right/left differences of the measurements for all 20 variables $(n=30)$ was as follows: menton $=0.735 \cdot($ neck length) $+0.329 \cdot$ (ramus length) $+0.331 \cdot($ frontal ramal inclination). The adjusted $R^{2}$ value was $0.765(P<.000)$. The regression equation between menton deviation and the right/left differences of the nine variables for the mandibular condyle $(n=30)$ was as follows: menton $=0.903$ • (neck length) $+0.005 \cdot$ (head volume). The adjusted $R^{2}$ value was $0.699(P<.000)$. The regression equation for the six variables of the glenoid fossa $(n=30)$ was as follows: menton $=-1.022 \cdot$ (vertical position of $\mathrm{AE}$ to FH). This equation showed that the adjusted $R^{2}$ value was 0.157 , indicating that the glenoid fossa had almost no effect on menton deviation $(P<.05)$. The regression equation for the five variables of the mandible $(n=30)$ was as follows: menton $=0.659 \cdot($ ramus length $)+0.407 \cdot($ frontal ramal inclination). In this equation, the adjusted $R^{2}$ value was $0.686(P<.000$, Table 5$)$.

\section{Discussion}

The degree of recognition of facial asymmetry can be affected by various factors. Ahn et al. [18] reported that the degree of asymmetry recognition increased when the degree of menton deviation increased. Lee et al. [17] also reported that menton deviation had the greatest effect on the degree of facial asymmetry recognition. In addition, Ferguson [16] evaluated the correlations between facial photographs and PA radiographs of patients with facial asymmetry and reported that the asymmetry 


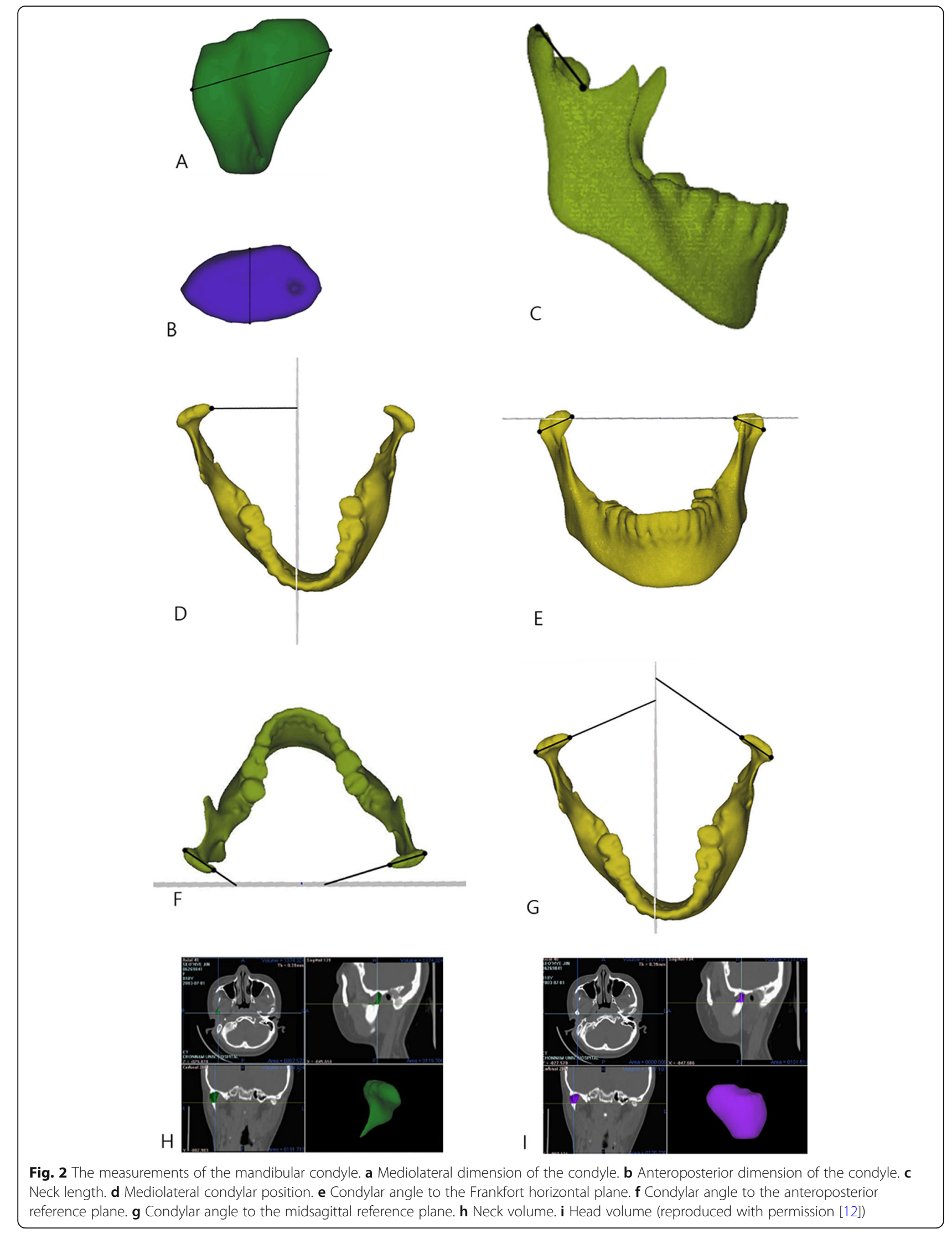




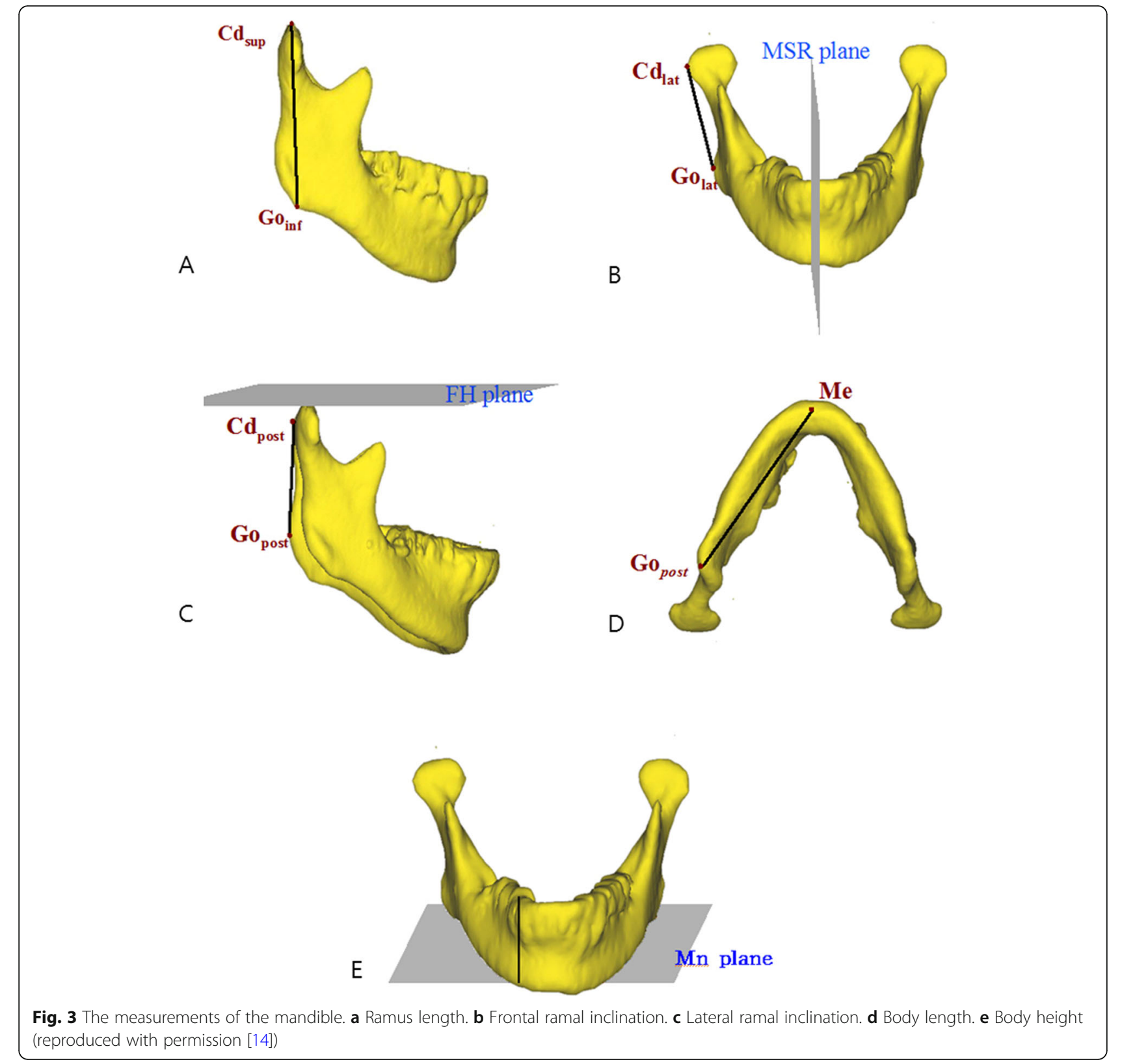

Fig. 3 The measurements of the mandible. a Ramus length. b Frontal ramal inclination. c Lateral ramal inclination. d Body length. e Body height (reproduced with permission [14])

Table 3 Description of the subjects $(n=30)$

\begin{tabular}{ll}
\hline Demographic characteristic & $\%$ or mean \pm SD \\
\hline Gender & \\
Female (\%) & 50.0 \\
Male (\%) & 50.0 \\
Age (years) & $23.2 \pm 3.8$ \\
Amount of menton deviation $\left(^{\circ}\right)$ & $5.7 \pm 2.5$ \\
ANB $\left(^{\circ}\right)$ & $-0.5 \pm 3.3$ \\
SN-MP $\left(^{\circ}\right)$ & $34.6 \pm 6.3$ \\
\hline
\end{tabular}

was recognized when menton deviation from the midline was $2^{\circ}$ or higher. McAvinchey et al. [19] investigated the perception of facial asymmetry in young adults and reported that the perception of asymmetry was affected by the amount of asymmetry. Menton deviation might be one of the primary contributing factors for recognition of facial asymmetry. Thus, it is necessary to evaluate the factors contributing to menton deviation in order to establish treatment plans for facial asymmetry. The present study examined the factors contributing to menton deviation in order to determine what contributed to facial asymmetry.

The subjects had skeletal class I or III malocclusion, in which the ANB angle was lower than $5^{\circ}$ on the lateral 
Table 4 The right/left differences of the measurements $(n=30)$

\begin{tabular}{|c|c|}
\hline Measurements & Mean \pm SD \\
\hline \multicolumn{2}{|l|}{ Mandibular condyle } \\
\hline Mediolateral dimension (mm) & $0.71 \pm 2.19$ \\
\hline Anteroposterior dimension (mm) & $0.38 \pm 1.10$ \\
\hline Neck length (mm) & $2.43 \pm 2.75$ \\
\hline Mediolateral condylar position (mm) & $0.73 \pm 2.08$ \\
\hline Condylar angle to $\mathrm{FH}\left({ }^{\circ}\right)$ & $2.09 \pm 8.13$ \\
\hline Condylar angle to $\mathrm{PO}\left(^{\circ}\right)$ & $-0.59 \pm 7.27$ \\
\hline Condylar angle to MSR $\left(^{\circ}\right)$ & $-3.28 \pm 13.42$ \\
\hline Neck volume $\left(\mathrm{mm}^{3}\right)$ & $341.99 \pm 443.68$ \\
\hline Head volume $\left(\mathrm{mm}^{3}\right)$ & $338.99 \pm 379.72$ \\
\hline \multicolumn{2}{|l|}{ Glenoid Fossa } \\
\hline Vertical position of RG to $\mathrm{FH}(\mathrm{mm})$ & $-0.31 \pm 2.02$ \\
\hline Vertical position of $\mathrm{AE}$ to $\mathrm{FH}(\mathrm{mm})$ & $-0.96 \pm 2.45$ \\
\hline Depth of glenoid fossa (mm) & $-0.66 \pm 1.35$ \\
\hline Sagittal position of RG to PO (mm) & $-0.10 \pm 1.51$ \\
\hline Sagittal position of AE to $\mathrm{PO}(\mathrm{mm})$ & $0.21 \pm 1.69$ \\
\hline Anterior angle of GF to $\mathrm{FH}\left({ }^{\circ}\right)$ & $-3.37 \pm 7.34$ \\
\hline \multicolumn{2}{|l|}{ Mandible } \\
\hline Ramus length (mm) & $3.27 \pm 4.22$ \\
\hline Frontal ramal inclination $\left(^{\circ}\right)$ & $3.98 \pm 4.53$ \\
\hline Lateral ramal inclination $\left(^{\circ}\right)$ & $3.25 \pm 5.42$ \\
\hline Body length (mm) & $1.16 \pm 3.32$ \\
\hline Body height (mm) & $0.19 \pm 1.42$ \\
\hline
\end{tabular}

$S D$ standard deviation, $F H$ Frankfort horizontal plane, $P O$ anteroposterior reference plane, $M S R$ midsagittal reference plane, $R G$ roof of glenoid fossa, $A E$ articular eminence, $G F$ glenoid fossa

cephalogram. Ngan et al. [20] compared the skeletal growth changes between class II division 1 and class I subjects and reported that the majority of the class II cases showed mandibular skeletal retrusion or a combination of horizontal and vertical abnormalities of the mandible, rather than maxillary protrusion. Previous studies $[3,21]$ compared the position and volume of the condyle in class I, II, and III and reported that the greatest condylar decentralization was observed in the class II group [21] and significantly lower condylar volume was observed in class II subjects compared to those in class I and III [3]. Thus, the present study excluded subjects with skeletal class II malocclusion due to the possible presence of mandibular growth disorders [3, 20, 21].

In this study, all measurements, including volumes of condylar neck and head, showed no significant differences between males and females. These results are inconsistent with the results of previous studies [3, 4]. Previous studies $[3,4]$ reported that the condylar volume was significantly higher in males than in females. This conflicting result is thought to be due to the fact that the previous studies $[3,4]$ was conducted on a sample
Table 5 Multiple linear regression analysis between the menton deviation and the right/left differences of the measurements $(n=30)$

\begin{tabular}{|c|c|c|c|c|}
\hline Measurements & Coefficient & $t$ & $P$ value & VIF \\
\hline \multicolumn{5}{|l|}{ For all variables ${ }^{a}$} \\
\hline Neck length & 0.735 & 3.223 & $0.003^{* *}$ & 2.315 \\
\hline Ramus length & 0.329 & 2.082 & $0.017^{*}$ & 2.346 \\
\hline Frontal ramal inclination & 0.331 & 3.031 & $0.005^{* *}$ & 1.430 \\
\hline \multicolumn{5}{|l|}{ For the mandibular condyle } \\
\hline Neck length & 0.903 & 3.698 & $0.000^{* * *}$ & 2.072 \\
\hline Head volume & 0.005 & 2.625 & $0.014^{*}$ & 2.072 \\
\hline \multicolumn{5}{|l|}{ For the glenoid fossa ${ }^{c}$} \\
\hline Vertical position of $\mathrm{AE}$ to $\mathrm{FH}$ & -1.022 & 2.567 & $0.016^{*}$ & NA \\
\hline \multicolumn{5}{|l|}{ For the mandible $^{d}$} \\
\hline Ramus length & 0.659 & 4.733 & $0.000^{* * *}$ & 1.363 \\
\hline Frontal ramal inclination & 0.407 & 3.305 & $0.003^{* *}$ & 1.363 \\
\hline
\end{tabular}

VIF variance inflation factor, $A E$ articular eminence, $F H$ Frankfort horizontal plane, $N A$ not available

${ }^{\text {a Adjusted }} R^{2}=0.765, P<0.000$

${ }^{\mathrm{b}}$ Adjusted $R^{2}=0.699, P<0.000$

${ }^{\text {CAdjusted }} R^{2}=0.157, P<0.05$

${ }^{\mathrm{d}}$ Adjusted $R^{2}=0.686, P<0.000$

${ }^{*} P<0.05$

${ }^{* *} P<0.01$

${ }^{* * *} P<0.001$

size of 200 and 94, respectively, while the present study was conducted on only 30 subjects.

In facial asymmetry, the explanatory power of the regression equation for all 20 variables for the mandibular condyle, glenoid fossa, and mandible was $76.5 \%$, and the neck length, ramus length, and frontal ramal inclination had positive influences on menton deviation. Multiple regression analysis of the anatomical structures affecting menton deviation showed that the explanatory power of the regression equation for the mandibular condyle was $69.9 \%$ and the neck length and head volume of the mandibular condyle had positive influences on menton deviation. The explanatory power of the regression equation for the glenoid fossa was $15.7 \%$, indicating that the glenoid fossa had little effect on menton deviation. The explanatory power of the regression equation for the mandible was $68.6 \%$ and the ramus length and frontal ramal inclination had positive influences on menton deviation (Table 5). The variance inflation factor for all variables was less than 3 , indicating that there was no multicollinearity. These results suggest that the right/left differences of the mandibular condyle and mandible can be used to predict menton deviation. Specifically, the right/left differences of neck length and ramus length contributed the most to menton deviation. However, it was not possible to predict menton deviation using the right/left difference of the glenoid fossa (Fig. 4). These results are caused by the mandibular asymmetry is 


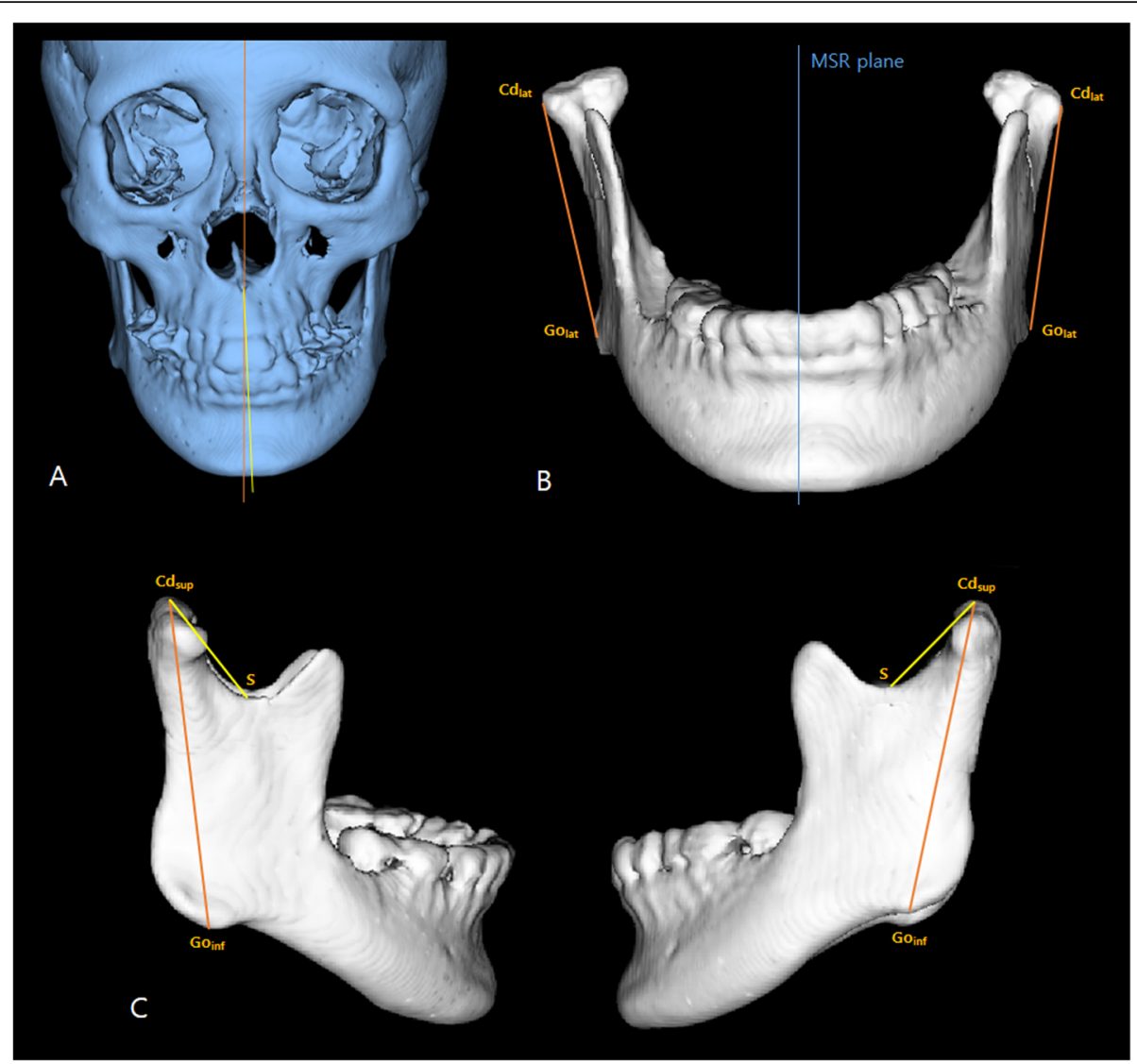

Fig. 4 A subject consistent with the results of this present study. a Menton is deviated to the left side. $\mathbf{b}$ The frontal ramal inclination is greater in the right side (non-deviated side) than the left side (deviated side). c The ramus length and neck length are greater in the right side (nondeviated side) than the left side (deviated side)

associated with the condylar growth center, which directly or indirectly regulates the size of the condyle and also the length of the condylar neck, ramus, and body of the mandible [22]. In the diagnosis of facial asymmetry patients, the difference between right and left side of mandible including mandibular condyle should be considered and a treatment plan should be established to improve it.

The present study had several limitations. Although the upper and middle thirds of the face have less effect on facial asymmetry than the lower third of the face [17, 19], there might be a maxillary asymmetry in facial asymmetry. The horizontal reference plane, FH plane, was defined as a plane passing through the right orbitale and right and left porions to exclude the asymmetry on orbitale points. Nevertheless, the effects of the maxillary asymmetry could not be completely ruled out, due to the use of ANS for measuring the menton deviation.

In addition, menton deviation can be influenced by other factors, such as functional adaptation and the surrounding neuromuscular system. Maki et al. [23] evaluated the correlations between the surrounding muscles and bone density in an asymmetrical mandible and reported that the asymmetrical mandible was associated with asymmetrical distributions of the highest mineralized cortical bone and that it was age dependent. Nakano et al. [24] evaluated changes in the calcified tissue of the mandibular condyle during altered muscle function and showed that both the mandible and the condyle modified their shape and size, as well as the trabecular bone of the condyle, during the shifting of the mandible to one side as it closed. Nur et al. [25] found that soft tissues compensated for hard tissues at the gonial level. In addition, Kurusu et al. [26] evaluated the relationship between occlusal force and mandibular condyle morphology and reported that occlusal force influenced not only maxillofacial morphology but also mandibular condyle morphology. Thus, further studies are needed to evaluate the effects of soft tissue and function to better understand the etiology of facial asymmetry.

In the literature, the condylar volume has been also related to the type of mandibular divergence [27]. In a study with ninety-four subjects, higher condylar volume was a common characteristic of low angle subjects 
compared to normal and high mandibular plane angle subjects. In this study, the differences according to the type of mandibular divergence were not evaluated. Thus, the role of the neck and ramus length related to the concept of mandibular divergence should be supported by new studies.

\section{Conclusions}

In facial asymmetry, the right/left differences in mandibular condyle and mandible have more impact on the menton deviation than the right/left differences in the glenoid fossa.

\section{Acknowledgements}

Not applicable

\section{Authors' contributions}

$\mathrm{MHO}$ performed the work and wrote the manuscript. JHC designed the study, evaluated the statistical results, and revised the manuscript. All authors read and approved the final manuscript.

\section{Funding}

This work was supported by the National Research Foundation of Korea (NRF) grant funded by the Korea government (No. 2019R1G1A1008831 \& 2018R1D1A1B07051057).

\section{Availability of data and materials}

Not applicable

\section{Ethics approval and consent to participate}

This retrospective study was performed after obtaining approval from the Institutional Review Board of at Chonnam National University Dental Hospital (CNUDH-EXP-2017-016).

\section{Consent for publication}

Not applicable

\section{Competing interests}

The authors declare that they have no competing interests.

Received: 1 April 2020 Accepted: 13 August 2020

Published online: 22 September 2020

\section{References}

1. Severt TR, Proffit WR. The prevalence of facial asymmetry in the dentofacial deformities population at the University of North Carolina. Int J Adult Orthodon Orthognath Surg. 1997;12:171-6.

2. Thiesen G, Gribel BF, Freitas MPM, Oliver DR, Kim KB. Mandibular asymmetries and associated factors in orthodontic and orthognathic surgery patients. Angle Orthod. 2018;88:545-51.

3. Saccucci M, D'Attilio M, Rodolfino D, Festa F, Polimeni A, Tecco S. Condylar volume and condylar area in class I, class II and class III young adult subjects. Head Face Med. 2012;8:34

4. Nota A, Caruso S, Ehsani S, Baldini A, Tecco S. Three-dimensional volumetric analysis of mandibular condyle changes in growing subjects: a retrospective cross-sectional study. Cranio. 2018;24:1-7.

5. Bruce RA, Hayward JR. Condylar hyperplasia and mandibular asymmetry: a review. J Oral Surg. 1968;26:281-90.

6. Proffit WR, Vig KW, Turvey TA. Early fracture of the mandibular condyles: frequently an unsusepected cause of growth disturbances. Am J Orthod. 1980;78:1-24

7. Huang YL, Pogrel MA, Kaban LB. Diagnosis and management of condylar resorption. J Oral Maxillofac Surg. 1997:55:114-9.

8. Trpkova B, Major P, Nebbe B, Prasad N. Craniofacial asymmetry and temporomandibular joint internal derangement in female adolescents: a posteroanterior cephalometric study. Angle Orthod. 2000;70:81-8.
9. Kim SJ, Lee KJ, Lee SH, Baik HS. Morphologic relationship between the cranial base and the mandible in patients with facial asymmetry and mandibular prognathism. Am J Orthod Dentofac Orthop. 2013;144:330-40.

10. Shibazaki-Yorozuya R, Yamada A, Nagata S, Ueda K, Miller AJ, Maki K. Threedimensional longitudinal changes in craniofacial growth in untreated hemifacial microsomia patients with cone-beam computed tomography. Am J Orthod Dentofac Orthop. 2014;145:579-94.

11. You KH, Lee KJ, Lee SH, Baik HS. Three-dimensional computed tomography analysis of mandibular morphology in patients with facial asymmetry and mandibular prognathism. Am J Orthod Dentofac Orthop. 2010;138:540.e1-8.

12. Oh MH, Kang SJ, Cho JH. Comparison of the three-dimensional structures of mandibular condyles between adults with and without facial asymmetry: a retrospective study. Korean J Orthod. 2017:48:73-80.

13. Ikeda M, Miyamoto JJ, Takada Jl, Moriyama K. Association between 3dimensional mandibular morphology and condylar movement in subjects with mandibular asymmetry. Am J Orthod Dentofac Orthop. 2017;151:324-34.

14. Cho JH, Lee KM, Park HJ, Hwang HS. 3-D CT image study of effect of glenoid fossa on menton deviation. J Korean Assoc Maxillofac Plast Reconstr Surg. 2011;33:337-45.

15. Kim JY, Kim BJ, Park KH, Huh JK. Comparison of volume and position of the temporomandibular joint structures in patients with mandibular asymmetry. Oral Surg Oral Med Oral Pathol Oral Radiol. 2016:122:772-80.

16. Ferguson JW. Cephalometric interpretation and assessment of facial asymmetry secondary to congenital torticollis. Int J Oral Maxillofac Surg. 1993:22:7-10

17. Lee GH, Cho HK, Hwang HS, Kim JC. Studies of relationship between P-A cephalometric measurements and visual facial asymmetry. Korean J Phys Anthrop. 1998;11:41-8.

18. Ahn JS, Hwang HS. Relationship between perception of facial asymmetry and posteroanterior cephalometric measurements. Korea J Orthod. 2001:31:489-98.

19. McAvinchey G, Maxim F, Nix B, Djordjevic J, Linklater R, Landini G. The perception of facial asymmetry using 3-dimensional simulated images. Angle Orthod. 2014:84:957-65.

20. Ngan PW, Byczek E, Scheick J. Longitudinal evaluation of growth changes in class II division 1 subjects. Semin Orthod. 1997:3:222-31.

21. Fraga MR, Rodrigues AF, Ribeiro LC, Campos MJ, Vitral RW. Anteroposterior condylar position: a comparative study between subjects with normal occlusion and patients with class I, class II division 1, and class III malocclusions. Med Sci Monit. 2013;19:903-7.

22. Erickson GE, Waite DE. Mandibular asymmetry. J Am Dent Assoc. 1974;89:1369-73.

23. Maki K, Miller AJ, Okano T, et al. Cortical bone mineral density in asymmetrical mandibles: a three-dimensional quantitative computed tomography study. Eur J Orthod. 2001;23:217-32.

24. Nakano H, Watahiki J, Kubota M, et al. Micro X-ray computed tomography analysis for the evaluation of asymmetrical condylar growth in the rat Orthod Craniofacial Res. 2003:6:168-72.

25. Nur RB, Çakan DG, Arun T. Evaluation of facial hard and soft tissue asymmetry using cone-beam computed tomography. Am J Orthod Dentofac Orthop. 2016;149:225-37.

26. Kurusu A, Horiuchi M, Soma K. Relationship between occlusal force and mandibular condyle morphology. Evaluated by limited cone-beam computed tomography. Angle Orthod. 2009;79:1063-9.

27. Saccucci M, Polimeni A, Festa F, Tecco S. Do skeletal cephalometric characteristics correlate with condylar volume, surface and shape? A 3D analysis. Head Face Med. 2012:8:15.

\section{Publisher's Note}

Springer Nature remains neutral with regard to jurisdictional claims in published maps and institutional affiliations. 